\title{
Primary Headache Disorders at a Tertiary Health Facility in Lagos, Nigeria: Prevalence and Consultation Patterns
}

\author{
Olajumoke Oshinaike, ${ }^{1}$ Oluwadamilola Ojo, ${ }^{2}$ Njideka Okubadejo, ${ }^{2}$ \\ Olaitan Ojelabi, ${ }^{1}$ and Akinola Dada ${ }^{1}$ \\ ${ }^{1}$ Department of Medicine, Lagos State University College of Medicine, GRA, Ikeja, Lagos, Nigeria \\ ${ }^{2}$ College of Medicine, University of Lagos, Idi-Araba, Lagos, Nigeria \\ Correspondence should be addressed to Olajumoke Oshinaike; olajumoke68@yahoo.com
}

Received 30 April 2013; Revised 15 October 2013; Accepted 28 October 2013; Published 23 January 2014

Academic Editor: Eberval G. Figueiredo

Copyright ( 2014 Olajumoke Oshinaike et al. This is an open access article distributed under the Creative Commons Attribution License, which permits unrestricted use, distribution, and reproduction in any medium, provided the original work is properly cited.

\begin{abstract}
Background. Primary headaches are underdiagnosed and undertreated, with a significant impact on social activities and work. Aim. To determine the last-year prevalence and health care utilization pattern of primary headaches at a tertiary centre. Methods. A cross-sectional study was carried out amongst staff of the Lagos State University Teaching Hospital in Lagos, Nigeria. 402 staff members were selected by simple random sampling and administered a detailed structured headache assessment questionnaire. Migraine and tension-type headache were diagnosed according to the criteria of the International Headache Society (2004). Results. The participants comprised 168 males and 234 females. The mean age was $36.9 \pm 7.9$ years. The overall headache prevalence was $39.3 \%$ with female predominance $(P<0.0001)$. Tension-type headache was the most prevalent at $72.8 \%$ and migraine at $18.9 \%$. Unclassifiable headache constituted $8.2 \%$. Migraine headache showed female preponderance $(P=0.000)$. $80.4 \%$ of participants did not seek medical consultation compared with $19.6 \%$ who did $(P=0.000)$. Of the latter, $83.9 \%$ consulted the general practitioner (GP), whilst $16.1 \%$ consulted the neurologist. Conclusions. Primary headache prevalence is high in our population. It is not recognised as that requiring care by most of the staff of this tertiary health facility; thus education is required to increase health care utilization.
\end{abstract}

\section{Introduction}

Headache is one of the most common neurological disorders [1] and accounts for multiple visits to the general physician and neurologist. Primary headaches cause significant disability with reduced efficiency, quality of life, and lost workdays [2-6]. Few receive appropriate diagnosis and adequate care. Migraine and tension-type headache are the most prevalent primary headache disorders.

Worldwide, the current global prevalence of primary headache is $47 \%$; migraine headache, $10 \%$; tension-type headache, 38\%; and chronic daily headache, 3\% [4]. The lifetime prevalence rates are higher: in men, $93 \%$ for headache of any kind, $8 \%$ for migraine, and 69\% for tension-type headache. In women, lifetime prevalence is $99 \%$ for headache of any kind, 25\% for migraine, and $88 \%$ for tension-type headache [7]. In Africa, data on headache prevalence is sparse. The 1-year prevalence of headache documented in rural south Tanzania was 23.1\% [8], whilst in Ethiopia the 1year prevalence of migraine was 3\% (4.2\% females and $1.7 \%$ males) with a peak age specific rate in the fourth decade [9]. Osuntokun et al. [10] in Nigeria documented the crude prevalence ratio of migraine headache to be 5.3 per 100 ( 5 per 100 in males and 5.6 per 100 in females).

The burden of headache is enormous. According to the World Health Organization (WHO), migraine ranks 19th amongst all causes of years lived with disability (YLDs). Rasmussen et al. documented that the burden of tensiontype headache is greater than that of migraine regarding absenteeism from work. In Sweden, migraine was noted to affect family, love life, and sex life almost as much as it affected work [11, 12]. Other studies have also documented significant effects on the partners of patients with migraine with $24 \%$ missing days of family or social activities and $12 \%$ 
avoiding plans for family and social activities due to proband's migraine. Some patients with migraine have reported the influence of the disease on their ability of good parenting, and a minority confirmed that they avoided having children because of their migraine $[13,14]$.

Headache burden can be reduced significantly by increasing awareness in the population, timely hospital visits, recognition of precipitating factors, and treatment. Published studies assessing the epidemiology of primary headache disorders are sparse in Nigeria. Knowledge of the prevalence and disability burden in this region would add to the framework of the Global campaign to reduce headache burden worldwide. We aimed to determine primary headache prevalence, its symptom profile, and pattern of health care utilization at a tertiary institution in urban Lagos, Nigeria, using the operational diagnostic criteria of the International Headache Society (IHS) [15].

\section{Methodology}

2.1. Study Site. The Lagos State University Teaching Hospital is a state owned tertiary institution located in Ikeja, a suburb of the city of Lagos and the capital of Lagos State, Nigeria. It provides easily accessible health care services for its staff and the people of Lagos state with a population of over 21 million.

2.2. Study Subjects. The study population included 402 workers of the Lagos State University Teaching Hospital, Lagos, Nigeria. The participants were selected from nurses, doctors, pharmacists, drivers, engineering staff, administrative staff, and security officers. The inclusion criterion was age 18 and above and being a staff of the hospital, whilst the exclusion criterion was refusal to participate in the study. Approval was granted from the Research and Ethics Committee of the Lagos state teaching hospital and consent was gotten from all participants.

2.3. Study Design. This was a hospital-based, cross-sectional survey in which the study participants were selected by systematic random sampling. The number of subjects from each department was determined by proportionate allocation based on the departmental staff strength.

2.4. Examination. The headache survey was performed by means of an interview based on a detailed pretested structured assessment questionnaire. The interviews were conducted under the supervision of the first author (O.O.Os). The headache assessment questionnaire contained an initial section for demographic data and the next section included a description of the current features of headache as well as its characteristics. Details of the research were communicated to the consenting participants at the beginning of the exercise. The participants were given the questionnaires to fill out and were recollected for review the following day. Subsequently, telephone interviews were conducted on all participants to corroborate the diagnosis reached based on the review of the questionnaires. Medical consultation was assessed by selfreported visits to the health care provider in the preceding year and treatment pattern was documented.

2.5. Diagnostic Criteria. Headache was diagnosed according to the criteria of the International Headache Society (2004) [15].

Migraine was diagnosed in subjects with recurrent, moderate to severe unilateral throbbing headache associated with nausea or vomiting or visual disturbances. The subjects with migraine were not subclassified. Tension-type headache was diagnosed when subjects suffered from bilateral or vertex tightness or pressure-like feeling in the absence of gastrointestinal or visual discomfort. Details of the diagnostic criteria for both migraine and tension-type headaches are shown in Appendix.

2.6. Data Analysis. All data were coded using the Statistical Package for the Social Sciences (SPSS) version 19.0.

The data were summarized using frequency tables, means, and standard deviations for continuous variables. Frequency and contingency tables were used for the categorical data. The level of significance was considered as $P<0.05$.

\section{Results}

3.1. Demographic Characteristics of Study Population. A total of 500 questionnaires were distributed, of which 402 were returned, giving a participation rate of $80.4 \%$. The remaining (19.6\%) had either misplaced the questionnaire, did not wish to continue with the study, or were not available for telephone interview after completion of the questionnaires The 402 staff members that completed the questionnaires and had telephone interviews comprised 221 (55\%) medical staff and 181 (45\%) nonmedical staff. There were 168 (41.8\%) males and $234(58.2 \%)$ females. Their ages ranged between 20 and 55 years with a mean of $36.9 \pm 7.9$ years (median 38.8, range 35 ). The ages of the males ranged between 20 and 55 years with a mean of $35.9 \pm 7.5$ years (median 35.9 , range 35 ), whilst that of the females ranged between 20 and 55 years with a mean of $37.6 \pm 8.5$ years (median 39 , range 35 ).

3.2. Prevalence of Headache Types. Overall, a total of $158 / 402$ $(39.3 \%)$ staff members had recurrent headaches. The prevalence in males was $23.8 \%$ (40/168) and females $50.4 \%$ $(118 / 234)$. Headache was significantly more common in females than in males. $P<0.001$ (Figure 1 ) and in the 4 th decade of life (Figure 2). The headache prevalence in medical staff staff members was $35.3 \%(78 / 221)$ compared to $42.5 \%$ (77/181) in nonmedical staff $P=0.069$.

The prevalence of migraine was $18.9 \%(30 / 158)$ and it was significantly higher in females $28 / 118(23.7 \%)$ than in males $2 / 40(5 \%), P<0.001$. The mean age of onset of migraine headache was $19.2 \pm 8.24$ years. Physical activity was the main aggravating factor and occurred in 25\% (10/40) of cases, whilst the relieving factors were rest in $62.5 \%(25 / 40)$ and over-the-counter analgesics in $17.5 \%(7 / 40)$ of cases. 


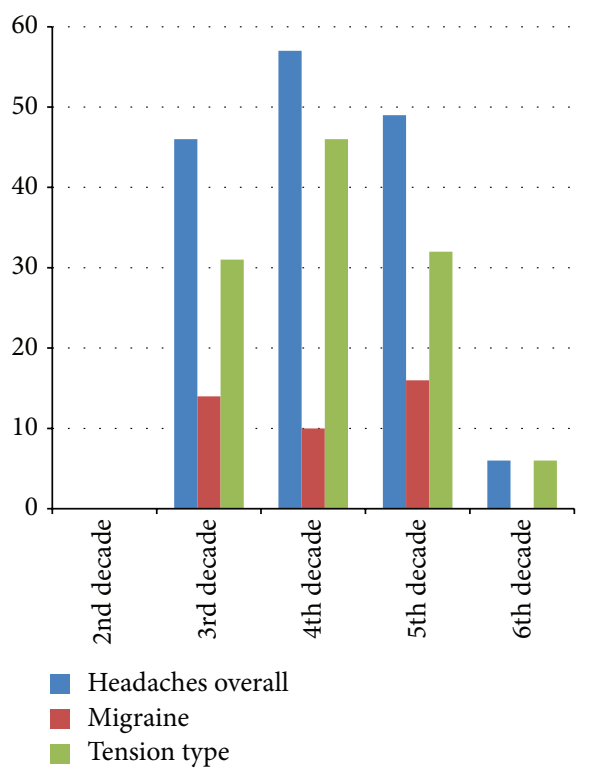

FIGURE 1: Prevalence of headache types in relation to age in decades.

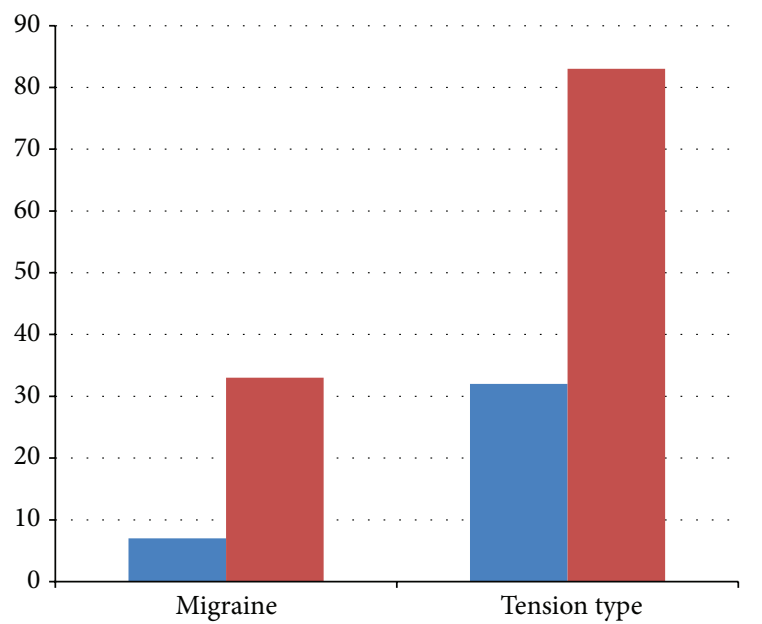

Male

Female

Figure 2: Gender difference in headache types.

The prevalence of tension-type headache was $72.8 \%$ (115/158). 83/115 (70.3\%) of females had tension-type headache compared with $32 / 40(80 \%)$ in males $(P<0.001)$. The mean age of onset of tension-type headache was $27.6+$ 10.7 years. The most common aggravating factor was physical activity, occurring in $42.6 \%(49 / 115)$ of cases, whilst the relieving factors were rest in $57.4 \%(66 / 115)$ and over-thecounter analgesic use in $31.3 \%$ (36/115) of cases.

$13 / 158$ (8.2\%) participants (7 females and 6 males) did not fulfill all criteria for migraine and tension-type headache and were classified as unclassifiable headache. No case of cluster headache was documented.
3.3. Pattern of Health Care Resource Utilization and Treatment. Participants who did not visit the health care provider for their headaches made up 127/158 (80.4\%) compared with $31 / 158(19.6 \%)$ who did $(P<0.001)$. Of the latter, $26 / 31$ $(83.9 \%)$ consulted the general practitioner (GP) whilst $5 / 31$ (16.1\%) the neurologist. Females made up 24/31 (77.4\%) of those who sought medical consultation, whilst the males made up $7 / 31(22.6 \%) ; P=0.69$. More participants with tension-type headache $21 / 31$ (67.7\%) sought medical consultation compared with those with migraine headache 5/31 (16.1\%).

The overall treatment included simple analgesics, 5/31 (16.1\%) nonsteroidal anti-inflammatory drugs (NSAIDS), 6/31 (19.4\%) ergotamine derivatives, 10/31 (32.3\%) amytriptilline, $9 / 31$ (29\%), and beta blockers 1/31 (3.2\%). None had a prescription for triptans.

\section{Discussion}

This cross-sectional prevalent study in our urban population estimated the 1-year prevalence of primary headaches to be $39.3 \%$. This finding is similar to the current global prevalence of $47 \%$ [4] and the $40 \%$ documented in the urban population of Brazil [16]. Ojini et al. [17] had earlier reported $46 \%$ at another teaching hospital in the same recruitment area as our centre of study. It is however lower than the population based study in Florianopolis, Brazil, which was $80.8 \%$ [18]. In comparison with studies conducted in working populations, Quesada-Vázquez and Rodríguez-Santanain Zimbabwe [19] had reported an overall headache prevalence of $37.1 \%$ which is also similar to our finding of $39.3 \%$. Takele et al. in a population of textile mill workers however reported a much lower prevalence of $16.4 \%$ [20]. The differences in rates may be due to variation in the criteria for the definition of headache disorders and the differing age groups of the population studied.

More women compared with men had higher prevalent rates for primary headache in this study as has been previously reported $[21,22]$. This has been attributed to the effect of female sex hormones specifically oestrogen.

We documented a prevalent rate of $18.9 \%$ for migraine in our study. This is higher than the global rate of $11 \%$ [7]. Takele et al. had reported a lower rate of $6.2 \%$, whilst Quesada-Vázquez and Rodríguez-Santana reported a higher rate of $30.8 \%$. One meta-analysis had indicated that the prevalence of migraine headache varied between different geographical regions, being lower in Europe than in North America but higher than in Asia and Africa [23]. Diversity of the population studied and racial differences in genetic vulnerability to migraine may also be contributory [24].

The well-known female preponderance in patients with migraine was also evident in our study. We found a significantly higher proportion of women with migraine headache, $8.2 \%$ compared to men, and $1.7 \%$. The higher rates in women are thought to be due to factors such as sensitivity to the oestrogen hormone, genetics, and differences in response to stress and pain perception. Premenstrual migraines are known to occur during or after the time when the female 
hormones, oestrogen and progesterone, decrease to their lowest levels [25]. We noted that the prevalent rate of migraine increased with age until the 4th decade when it started to decline. Tekle Haimanot [9] in Ethiopia had also documented a decline after a peak in the fourth decade of life.

The prevalent rate of tension-type headache in our study was $72 \%$. This finding is much higher than the $47.7 \%$ documented in Zimbabwe [19], the $25.5 \%$ by Quesada-Vázquez et al. in Cuba [26], and $11.2 \%$ reported in Oman [27]. It is however similar to the $78 \%$ and $86 \%$ reported by Rasmussen and Russell, respectively [28, 29]. There has been wide variations and differences in the epidemiology of tension-type headache across different cultures [4]. These variations may result from differences in study design, study population, inclusion or exclusion of cases of infrequent episodic TTH, and overlap with probable migraine, cultural and environmental differences, or even genetic factors [30].

A significant proportion, $80.4 \%$, of the participants in our study did not visit the health care provider for treatment of their headache disorders even in the setting of a tertiary health care facility. This trend had been documented in previous studies. Lipton et al. reported that $34 \%$ of the participants in their study did not seek medical consultation for their headaches [31]. In another study, he also reported that almost half of the study population had not utilized the health care system for their headaches [32]. Majority of headache sufferers never seek health care utilization probably as a result of ignorance. In our study, a larger percentage $83.9 \%$ of those that utilized the health care system consulted the general practitioner (GP), whilst only $16.1 \%$ consulted the neurologist. Kristoffersen et al. [33] in their study reported $80 \%$ rate of GP consultation and 19\% rate of neurology consultation which is similar to our findings.

\section{Conclusion}

Education on headache disorders as a substantial health problem and the benefit of health care utilization on the quality of life of headache sufferers need to be improved at all levels. Collaboration with policy-makers to plan and set up headache-related health-care services appropriate to local needs should be encouraged. Provision of additional training for general practitioners who attend to the bulk of patients with primary headache in this environment also cannot be over-emphasized.

\section{Limitations}

Our limitation includes lack of data on headache burden as this may probably explain the low percentage of health care utilization.

\section{Appendix}

The International Classification of Headache Disorders (2004).

\section{Migraine Headache}

(i) $\geq 5$ attacks lasting $4-72$ hours (ii) $\geq 2$ of the following 4
(a) Unilateral location
(b) Pulsating quality
(c) Moderate or severe intensity
(d) Aggravation by routine physical activity

(iii) $\geq 1$ of the following

(a) Nausea and/or vomiting

(b) Photophobia and phonophobia

(iv) Not attributable to any other disorder

Tension-Type Headache

(i) $\geq 10$ attacks lasting 30 minutes to 7 days

(ii) $\geq 2$ of the following 4

(a) Bilateral location

(b) Pressing/tightening (non-pulsating) quality

(c) Mild or moderate intensity

(d) Not aggravated by routine physical activity

(iii) No nausea or vomiting

(iv) One or either photophobia or phonophobia

(v) Not attributed to another disorder.

\section{Conflict of Interests}

The authors declare that they have no conflict of interests.

\section{Acknowledgment}

The authors are grateful to the staff and management of the Lagos State University Teaching Hospital for their assistance and co-operation.

\section{References}

[1] P. Andlin-Sobocki, B. Jönsson, H. Wittchen, and J. Olesen, "Cost of disorders of the brain in Europe," European Journal of Neurology, vol. 12, no. 1, pp. 1-27, 2005.

[2] J. Edmeads, H. Findlay, P. Tugwell, W. Pryse-Phillips, R. F. Nelson, and T. J. Murray, "Impact of migraine and tension-type headache on life-style, consulting behaviour, and medication use: a Canadian population survey," Canadian Journal of Neurological Sciences, vol. 20, no. 2, pp. 131-137, 1993.

[3] J. T. Osterhaus, D. L. Gutterman, and J. R. Plachetka, "Healthcare resource and lost labour costs of migraine headache in the US," PharmacoEconomics, vol. 2, no. 1, pp. 67-76, 1992.

[4] L. J. Stovner, K. Hagen, R. Jensen et al., "The global burden of headache: a documentation of headache prevalence and disability worldwide," Cephalalgia, vol. 27, no. 3, pp. 193-210, 2007.

[5] W. F. Stewart, J. A. Ricci, E. Chee, D. Morganstein, and R. Lipton, "Lost productive time and cost due to common pain conditions in the US workforce," Journal of the American Medical Association, vol. 290, no. 18, pp. 2443-2454, 2003. 
[6] J. Zwart, G. Dyb, K. Hagen et al., "Depression and anxiety disorders associated with headache frequency. The Nord-Trøndelag Health Study," European Journal of Neurology, vol. 10, no. 2, pp. 147-152, 2003.

[7] J. R. Saper, S. D. Silberstein, C. D. Gordon, R. L. Hamel, and S. Swidan, Handbook of Headache Managemented, Lippincott Williams \& Wilkins, Philadelphia, Pa, USA, 2nd edition, 1999.

[8] W. Dent, H. K. Spiss, R. Helbok, W. B. P. Matuja, S. Scheunemann, and E. Schmutzhard, "Prevalence of migraine in a rural area in South Tanzania: a door-to-door survey," Cephalalgia, vol. 24, no. 11, pp. 960-966, 2004.

[9] R. Tekle Haimanot, B. Seraw, L. Forsgren, K. Ekbom, and J. Ekstedt, "Migraine, chronic tension-type headache, and cluster headache in an Ethiopian rural community," Cephalalgia, vol. 15, no. 6, pp. 482-488, 1995.

[10] B. O. Osuntokun, A. O. Adeuja, V. A. Nottidge et al., "Prevalence of headache and migrainous headache in Nigerian Africans: a community-based study," East African Medical Journal, vol. 69, no. 4, pp. 196-199, 1992.

[11] B. K. Rasmussen, R. Jensen, and J. Olesen, "Impact of headache on sickness absence and utilisation of medical services: a Danish population study," Journal of Epidemiology and Community Health, vol. 46, no. 4, pp. 443-446, 1992.

[12] M. Linde and C. Dahlöf, "Attitudes and burden of disease among self-considered migraineurs: a nation-wide populationbased survey in Sweden," Cephalalgia, vol. 24, no. 6, pp. 455465, 2004.

[13] S. W. Hamelsky, R. B. Lipton, and W. F. Stewart, "An assessment of the burden of migraine using the willingness to pay model," Cephalalgia, vol. 25, no. 2, pp. 87-100, 2005.

[14] R. B. Lipton, J. N. Liberman, K. B. Kolodner, M. E. Bigal, A. Dowson, and W. F. Stewart, "Migraine headache disability and health-related quality-of-life: a population-based case-control study from England," Cephalalgia, vol. 23, no. 6, pp. 441-450, 2003.

[15] Headache Classification Subcommittee of the International Headache Society, "The international classification of headache disorders: 2nd edition," Cephalalgia, vol. 24, supplement 1, pp. 9-160, 2004.

[16] W. L. Sanvito, P. H. Monzillo, M. F. P. Peres et al., "The epidemiology of migraine in medical students," Headache, vol. 36 , no. 5, pp. 316-319, 1996.

[17] F. Ojini, N. Okubadejo, and M. Danesi, "Prevalence and clinical characteristics of headache in medical students of the University of Lagos, Nigeria," Cephalalgia, vol. 29, no. 4, pp. 472-477, 2009.

[18] L. P. Queiroz, L. M. Barea, and N. Blank, "An epidemiological study of headache in Florianopolis, Brazil," Cephalalgia, vol. 26, no. 2, pp. 122-127, 2005.

[19] A. J. Quesada-Vázquez and N. Rodríguez-Santana, “The prevalence of primary headaches in the working population at a psychiatric hospital in Zimbabwe," Revista de Neurología, vol. 43, no. 3, pp. 129-131, 2006.

[20] G. M. Takele, R. Tekle Haimanot, and P. Martelletti, "Prevalence and burden of primary headache in Akaki textile mill workers, Ethiopia," Journal of Headache and Pain, vol. 9, no. 2, pp. 119128,2008 .

[21] E. A. MacGregor, J. D. Rosenberg, and T. Kurth, "Sex-related differences in epidemiological and clinic-based headache studies," Headache, vol. 51, no. 6, pp. 843-859, 2011.

[22] C. S. Liverman, J. W. Brown, R. Sandhir, R. M. Klein, K. McCarson, and N. E. J. Berman, "Oestrogen increases nociception through ERK activation in the trigeminal ganglion: evidence for a peripheral mechanism of allodynia," Cephalalgia, vol. 29, no. 5, pp. 520-531, 2009.

[23] A. I. Scher, W. F. Stewart, J. Liberman, and R. B. Lipton, "Prevalence of frequent headache in a population sample," Headache, vol. 38, no. 7, pp. 497-506, 1998.

[24] W. F. Stewart, R. B. Lipton, and J. Liberman, "Variation in migraine prevalence by race," Neurology, vol. 47, no. 1, pp. 52-59, 1996.

[25] B. L. Peterlin, S. Gupta, T. N. Ward, and A. MacGregor, "Sex matters: evaluating sex and gender in migraine and headache research," Headache, vol. 51, no. 6, pp. 839-842, 2011.

[26] A. J. Quesada-Vázquez, L. J. Contreras-Maure, A. ÁlvarezAliaga, and E. R. Traba-Tamayo, "Prevalence of primary headaches in a rural population in Cuba," Revista de Neurologia, vol. 49, no. 3, pp. 131-135, 2009.

[27] D. Deleu, M. A. Khan, and T. A. H. Al Shehab, "Prevalence and clinical characteristics of headache in a rural community in Oman," Headache, vol. 42, no. 10, pp. 963-973, 2002.

[28] B. K. Rasmussen, "Epidemiology of headache," Cephalalgia, vol. 15, no. 1, pp. 45-58, 1995.

[29] M. B. Russell, N. Levi, J. Šaltyte-Benth, and K. Fenger, “Tensiontype headache in adolescents and adults: a population based study of 33,764 twins," European Journal of Epidemiology, vol. 21, no. 2, pp. 153-160, 2006.

[30] K. Sahler, "Epidemiology and cultural differences in tensiontype headache," Current Pain and Headache Reports, vol. 16, no. 6, pp. 525-532, 2012.

[31] R. B. Lipton, W. F. Stewart, and D. Simon, "Medical consultation for migraine: results from the American Migraine Study," Headache, vol. 38, no. 2, pp. 87-96, 1998.

[32] R. B. Lipton, A. I. Scher, T. J. Steiner et al., "Patterns of health care utilization for migraine in England and in the United States," Neurology, vol. 60, no. 3, pp. 441-448, 2003.

[33] E. S. Kristoffersen, R. B. Grande, K. Aaseth, C. Lundqvist, and M. B. Russell, "Management of primary chronic headache in the general population: the Akershus study of chronic headache," Journal of Headache and Pain, vol. 13, no. 2, pp. 113-120, 2012. 


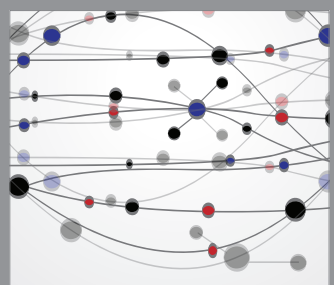

The Scientific World Journal
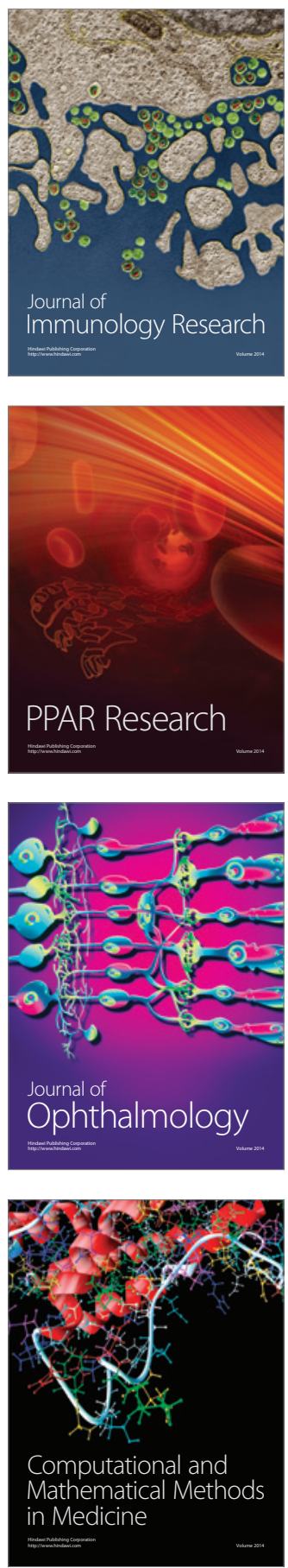

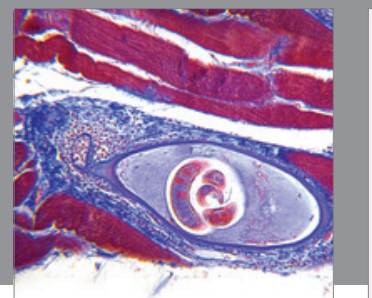

Gastroenterology

Research and Practice
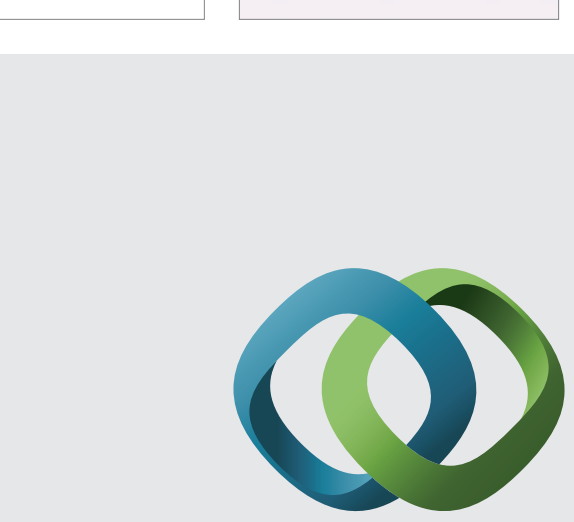

\section{Hindawi}

Submit your manuscripts at

http://www.hindawi.com
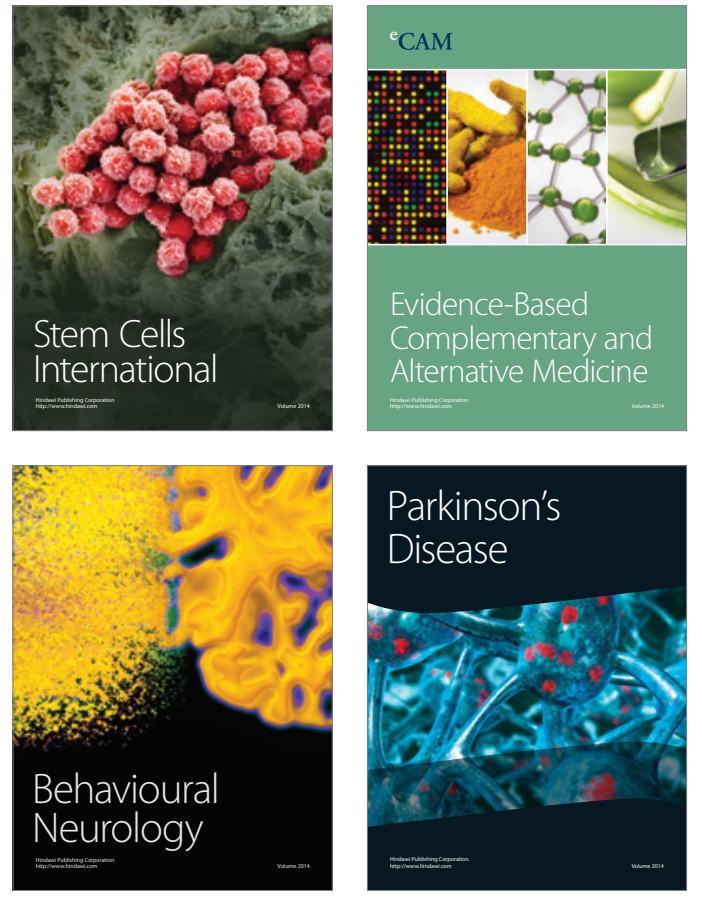
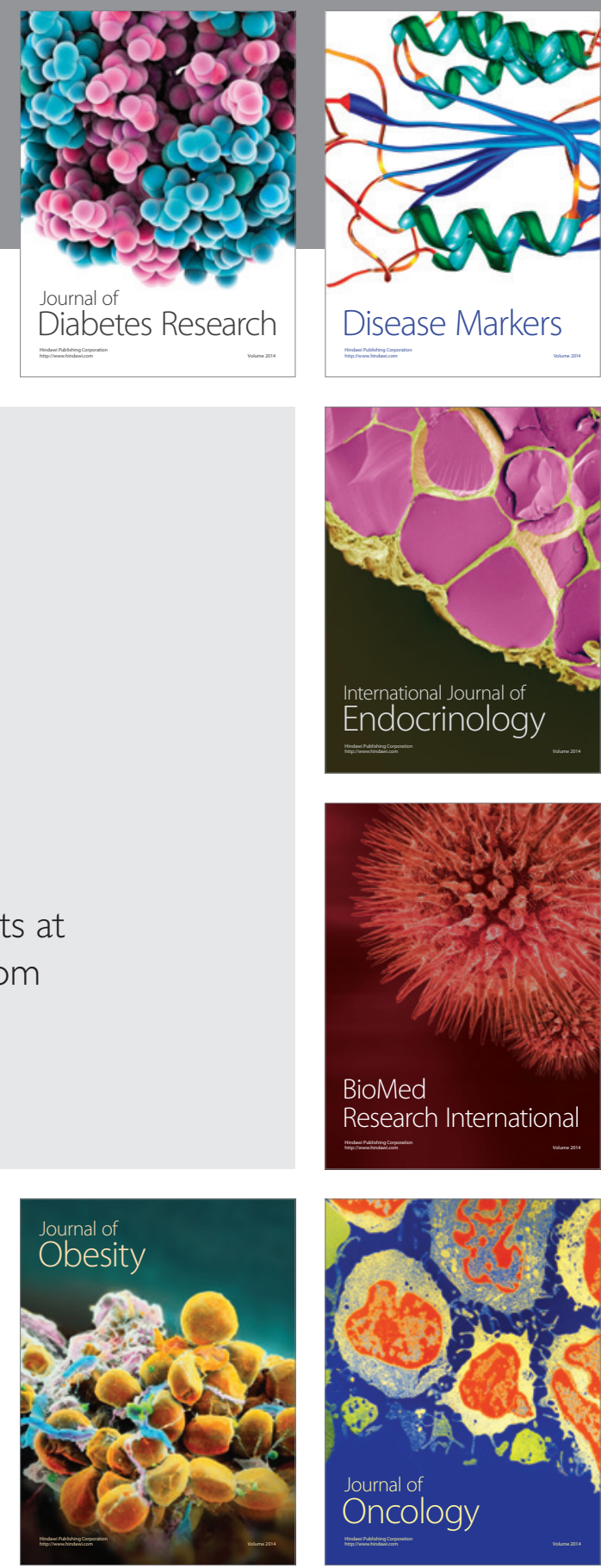

Disease Markers
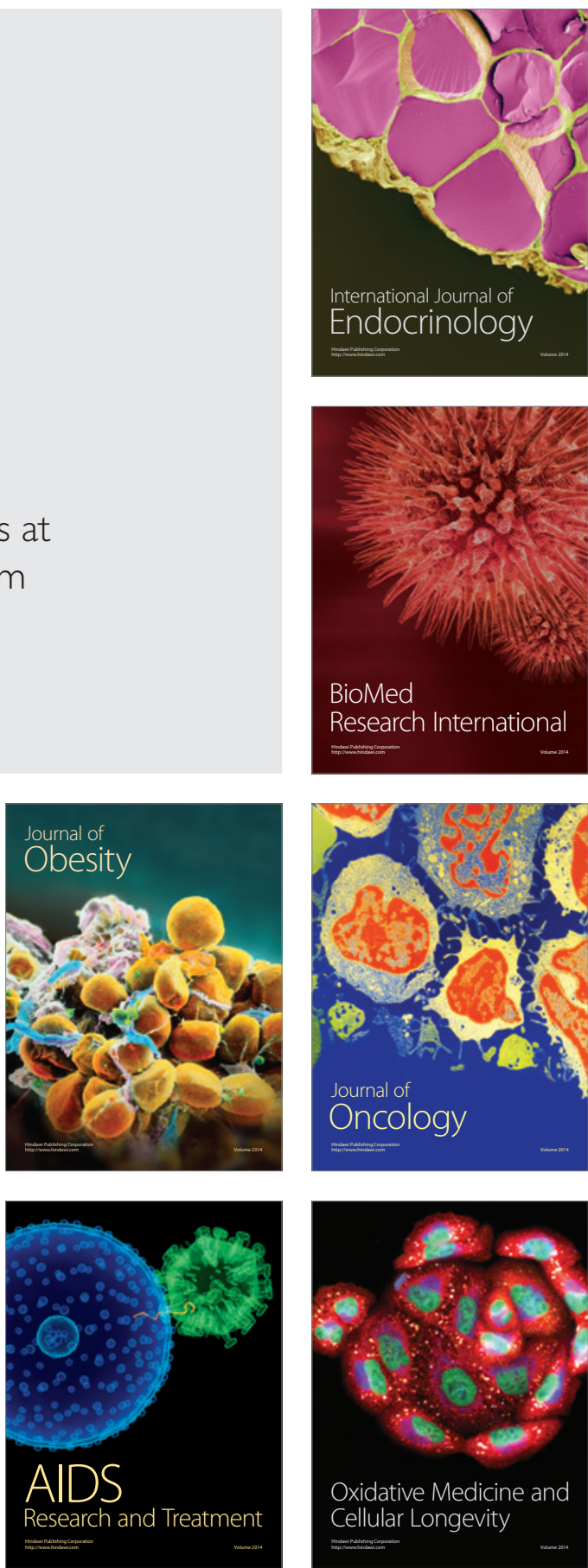